\title{
Redescription of Steinernema scapterisci Nguyen and Smart, 1990: (Steinernematidae)
}

\author{
H. S. Singh*, M alti, Neetu Singh and A nshu Chaudhary \\ Department of Zoology, Ch. C. S. University, Meerut- 250004 (U.P.), INDIA \\ *Corresponding author. Email : hirdaya_singh@ rediffmail.com
}

Abstract: Present communication deals with redescription of the insect parasitic nematode, Steinernema scapterisc Nguyen and Smart, 1990, collected from the mole cricket, Gryllotalpa africana at Khurja, district (U.P.). The original description suffers from some morphological variations in the testis, tail and vulvular region.

Keywords: Entomopathogenic nematodes, Steinernema scapterisci, Gryllotalpa africana, Taxonomy

\section{INTRODUCTION}

Entomopathogenic nematodes in the family Steinernematidae Travassos, 1927 have great potential for use as biological control agents for soil, inhabiting insect pest (Gaugler and Kaya, 1990; Kaya and Gaugler, 1993). Recent surveys related to this family have reported the presence of new isolates/species from Sri Lanka, (Amara Singhe et al., 1994), Puerto Rico (Roman and Figueroa, 1994), Portugal (Rosa et al., 1994) Canada (Mracek and Webster, 1993), Argentina (Stock, 1995), Korea (Choo et al., 1995; Stock et al., 1997) and China (Jian et al., 1997). Besides this, a number of EPN surveys in tropical and subtropical regions have also been conducted by several workers. But specific survey for members of Steinernematidae in India in general and Meerut in particular is still awaited. Thus, with the view to make of general survey of this group in Meerut region, present investigation was started with the hope of its subsequent use as biological control agent of soil inhabiting insect of economic importance.

\section{MATERIALS AND METHODS}

Commonly available insect, mole cricket Gryllotalpa africana for the present investigations were collected from soil from different localities of Meerut and identified with the help of classical work of Imms (1960) and Davies (1977). Insects were anesthetized with the help of Chloroform. Subsequently, a thorough examination of their whole body cavity was made under stereoscopic binocular microscope. Nematode parasites were picked up with the help of a fine glass dropper. After removal from host, parasites were washed in normal saline and fixed either in A.F.A. fixative or in hot $70 \%$ Alcohol. For the study of morphology, parasites were cleared in Glycerin or Lacto phenol. Diagrams were made with the help of Camera Lucida to support the morphological observations.

\section{RESULTS}

Worms collected by author exhibit close resemblance with Steinernema scapterisci Nguyen and Smart, 1990. However, it exhibits minor variations in some morphological features besides differences and measurements in various body parts. It is therefore briefly redescribed as such (Tables 1 and 2). Body elongated and cylindrical. Females are 2 to 3 times longer than males. Males provided with curved spike like tail. In both male and female specimens immediately behind the oesophageal bulb with exact two vesicle like structure, place one above the other. Sometimes, it is seen that in the lumen of these vesicle, there exists some intravesicular structures are untethered clusters or enucleate spherical bodies embedded in amorphous matrix of vesicular lumen. The morphological details of male and female specimens are given as follows:

$\mathrm{M}$ ale (Platel and PlatelII): Body of male worm measures 1.3-1.7 mm in length. Maximum width was recorded in equatorial region of the body, $0.11-0.13 \mathrm{~mm}$. Body covering smooth, striations not visible. A pair of amphids is present out side the buccal capsule. Oesophagus muscular, well developed and measures $0.16-0.17 \mathrm{~mm}$ in length. Unlike other nematodes, oesophagus is not differentiated into corpus and isthmus. But the posterior part is slightly swollen giving appearance of oesophageal bulb. Intestine is simple and occupy the whole width of parasite and finally converging into anus. Testis single reflexed occupying $2 / 3^{\text {rd }}$ of the length of parasite from the posterior end. At the anterior end, testis becomes thin walled tube and get coiled. Anus is sub-terminal in location at $0.040-0.046 \mathrm{~mm}$ from the posterior end. Tail of male was short and blunt measuring 0.04-0.06 mm in length. 


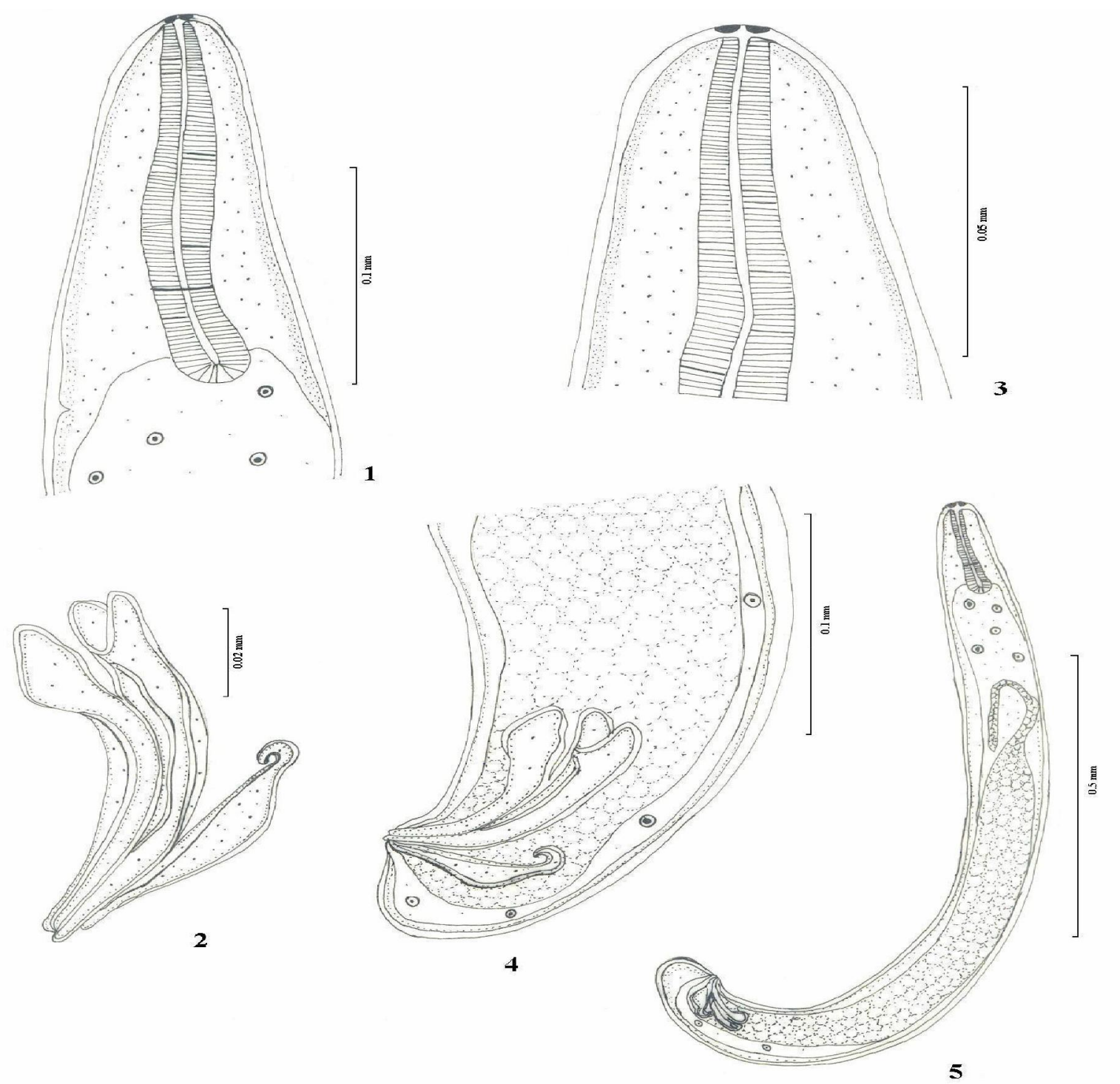

Plate I. S. scapterisci Nguyen and Smart, 1990 male Figs. 1-5: 1) Anterior region. 2) Spicule 3) Anterior region enlarged 4) Posterior region enlarged, 5) M ale entire.

Spicule present and the bifurcated into two parts. Spicule tubular in outline and covered with sclerotized cuticle. Proximal spicule larger measuring 0.07-0.09 mm. Capitulum of proximal spicule broad and very well set off from the corpus or calomus, broad, flattened which tapers to form the last part called blade or lamina, with the help of a narrow neck like constriction. Distal spicule comparatively short, measuring 0.05-0.07 $\mathrm{mm}$ in length. Gubernaculum boat shaped, with anterior part thin, long and ventrally curved. Spicule glide along gubernaculum in two grooves separated by a needle- shaped cuneus. Eleven or 12 pairs of single genital papillae observed. Female (Platell and Plate IV): Body of worm cylindrical measures 3.3-4.0 mm in length and comparatively longer than that the male. Width of worm is $0.21-0.25 \mathrm{~mm}$. Striations not visible in any part of the body. Mouth terminal, body cavity inconspicuous. Nerve ring located at a distance of $0.15 \mathrm{~mm}$ from the anterior tip. Oesophagus simple, cylindrical with slightly expended posterior part, measuring 0.21-0.25 mm in length. However, posterior most part somewhat bulbous forming the oesophageal bulb measuring $0.042-0.045 \times 0.050-0.052 \mathrm{~mm}$. Intestine simple and long tube, which terminates into anus. Anus located at a distance of $0.06-0.08 \mathrm{~mm}$ from the posterior end. Female nematodes possess two sets of reproductive organs, didelphic. Vulva equatorial in location. Vagina highly muscular and extended in the form of two finger like projections called epiptygma. Uteri amphidelphic and open into rounded spermatheca. Ovaries from the either side extend towards middle and cross each other at the level of vulva giving ' $\mathrm{X}$ ' like appearance. Eggs small rounded in outline, thin shelled measuring 0.04-0.05 mm in diameter. In the distal part of uterus eggs are fully segmented. Tail is bluntly conoid measuring 0.020-0.023 $\mathrm{mm}$ in length. 


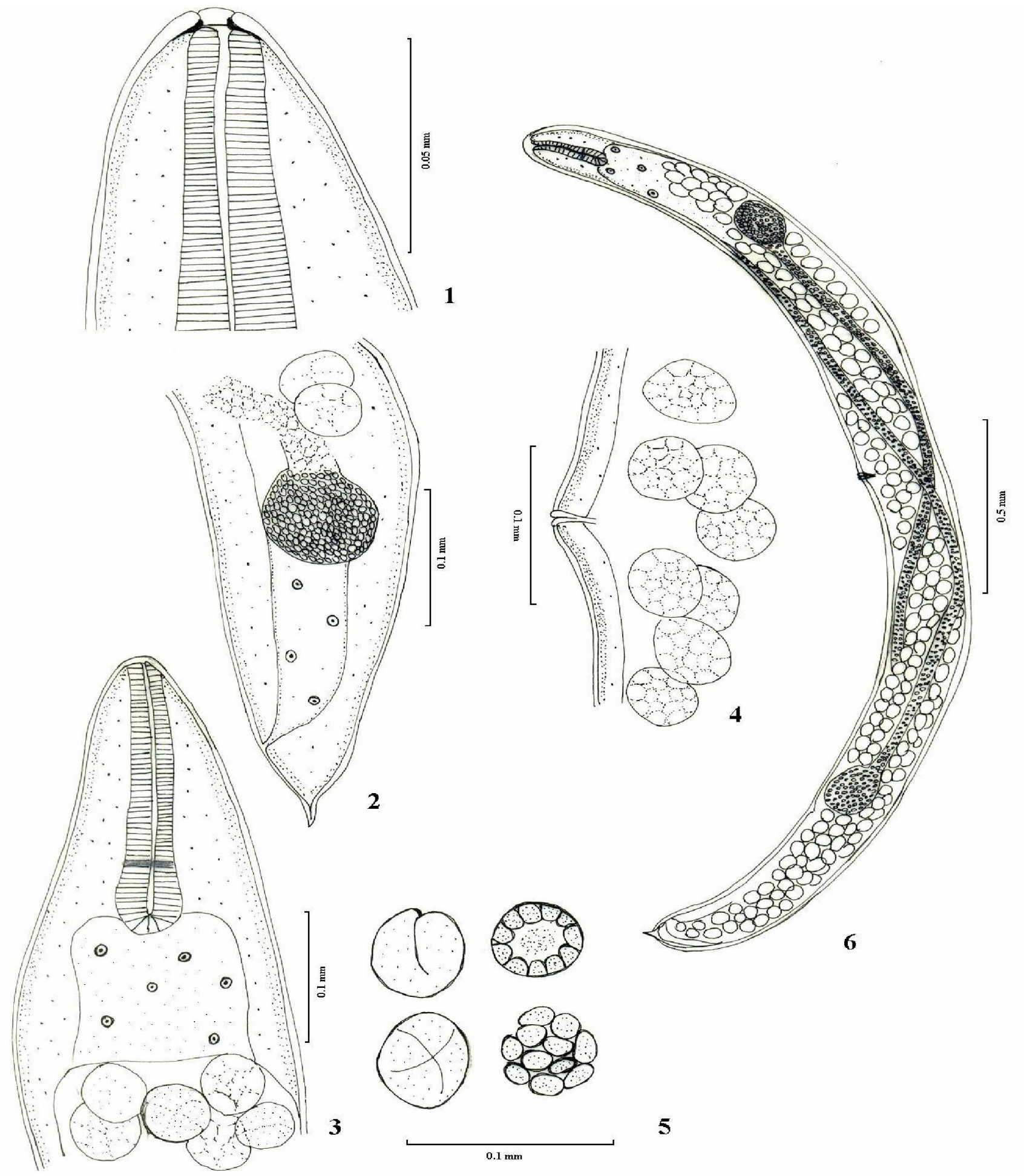

Plate II. S. scapterisci Nguyen and Smart, 1990 female Figs.1- 6. 1) Anterior region enlarged 2) Posterior region enlarged 3) Anterior region 4) Vulva 5) Eggs, 6) Female entire.

\section{DISCUSSION}

Steinernema scapterisci was first of all reported by Nguyen and Smart (1990) from Scapteriscus vicinus at Uruguay, South America. During course of study, nematode parasite of Gryllotalpa africana, investigators came across a few specimens of host infected with nematode parasite of genus Steinernema Travassos, 1927. On subsequent study, it was found that worms at disposal of the authors resembles closely with $\mathrm{S}$. scapterisci, Nguyen and Smart (1990). However, the original description of S. scapterisci suffers from some morphological lapses, minor variations in a few features 

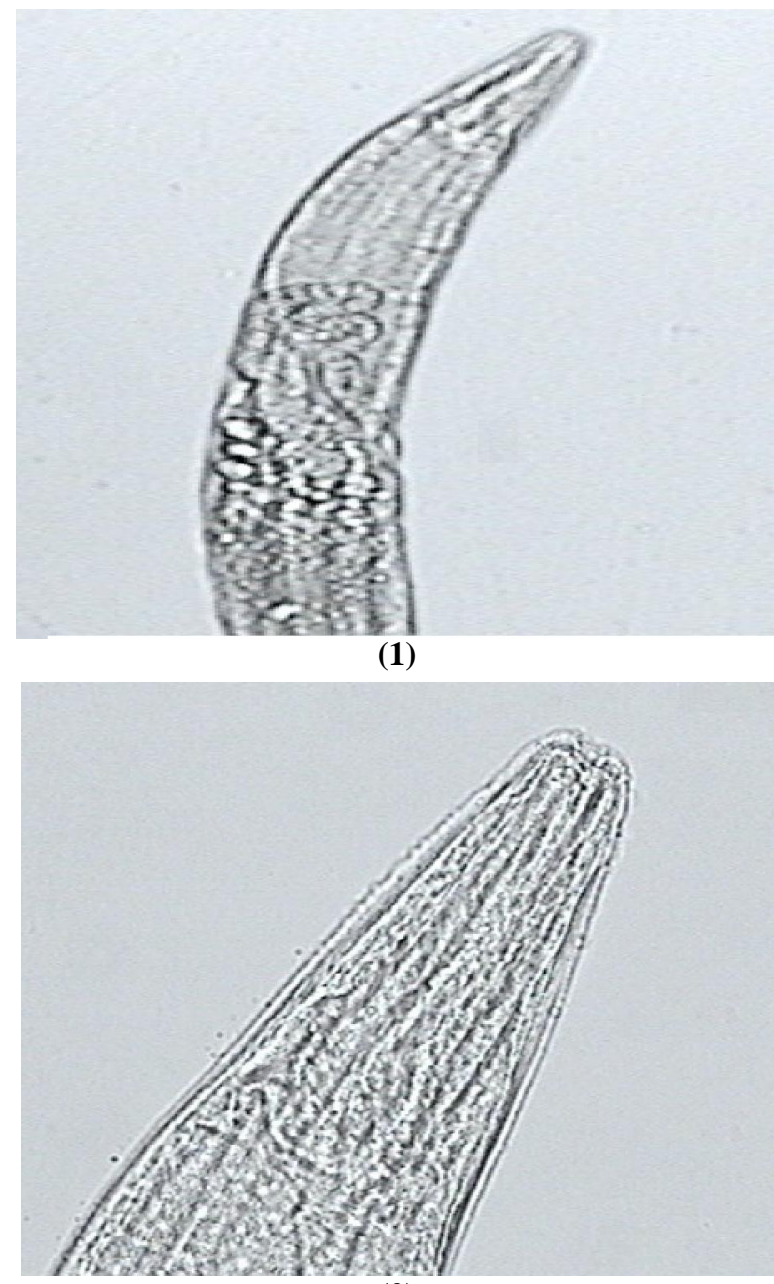

(2)

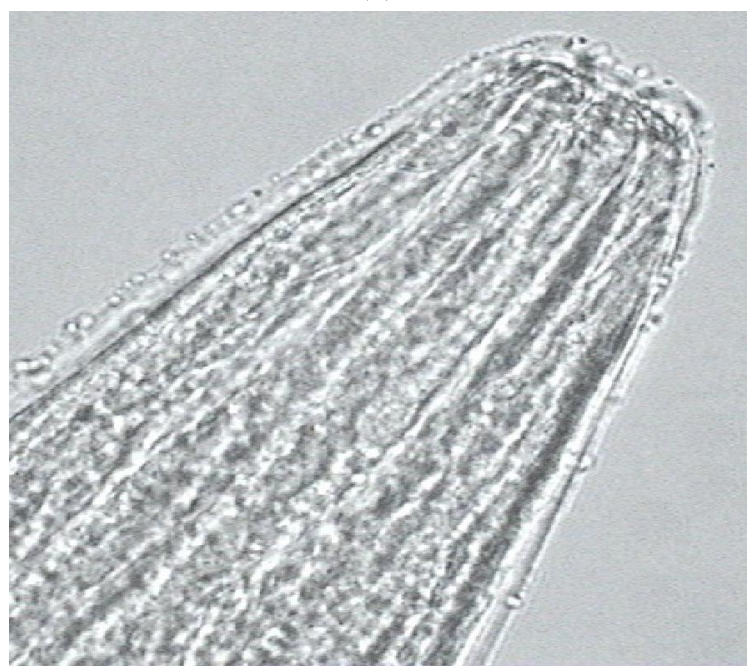

(3)

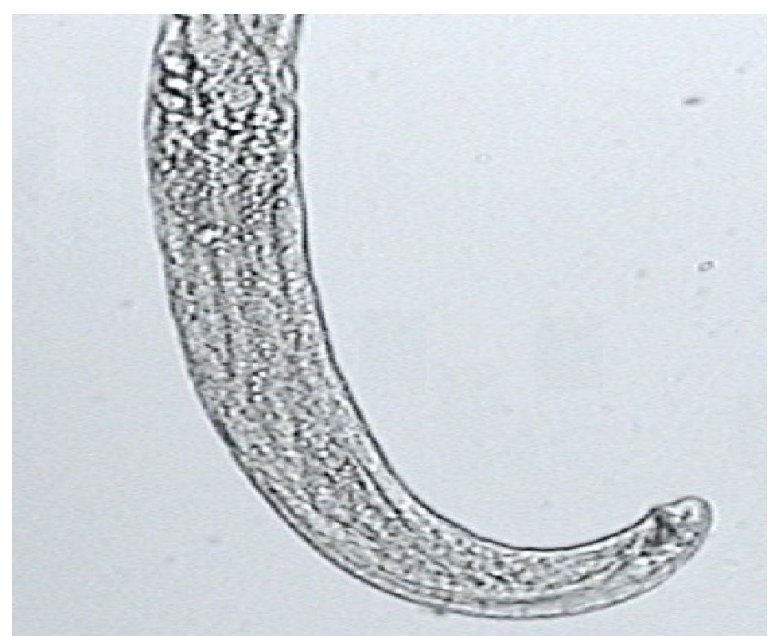

(4)

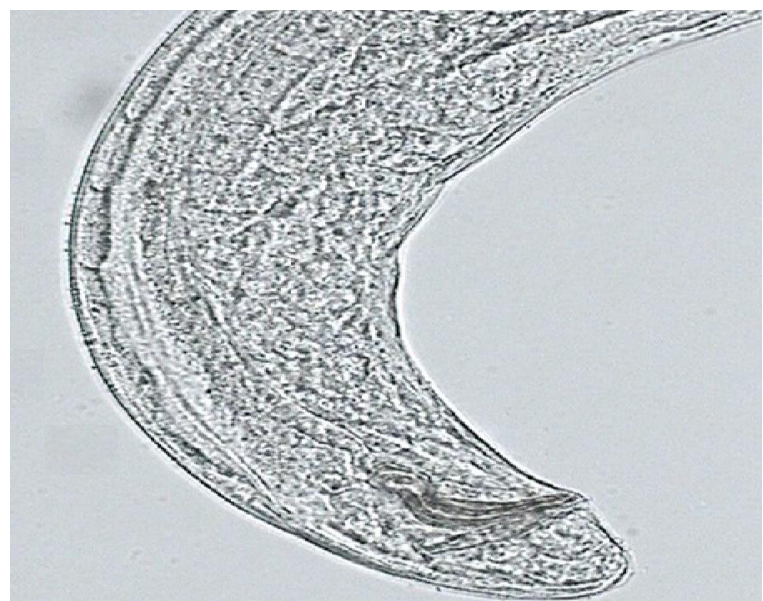

(5)

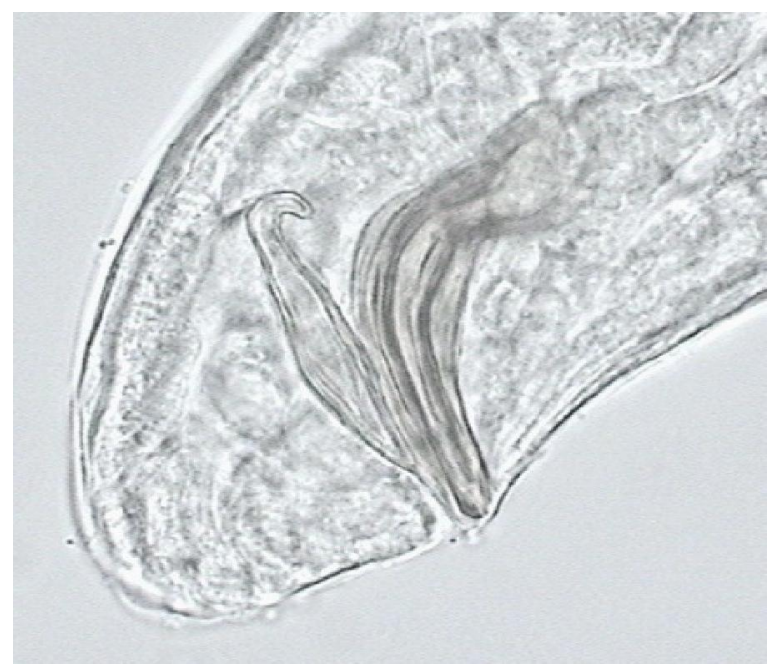

(6)

PlateIII. S. scapterisci Nguyen and Smart 1990 male Figs. 1-6. 1) Photomicrographs of anterior region x 100, 2) Photomicrographs of anterior region $x 400,3)$ Photomicrographs of anterior region $\times 1000$, 4) Photomicrographs of posterior region $x 100,5$ ) Photomicr ographs of posterior region x 400,6) Photomicrographs of posterior $x 1000$.

have also been noticed besides the differences in measurements of various body parts. It is, therefore, redescribed here in as such. The important variations which were noticed in the specimens at disposal of writers are: Testis in the present specimens found extended beyond the equatorial region of the body, in the original description forwarded by Nguyen and Smart (1990), male worm are equipped small spike like tail and vulva in female specimens less protruded. These variations in the present specimens could be due to presence of parasite in 


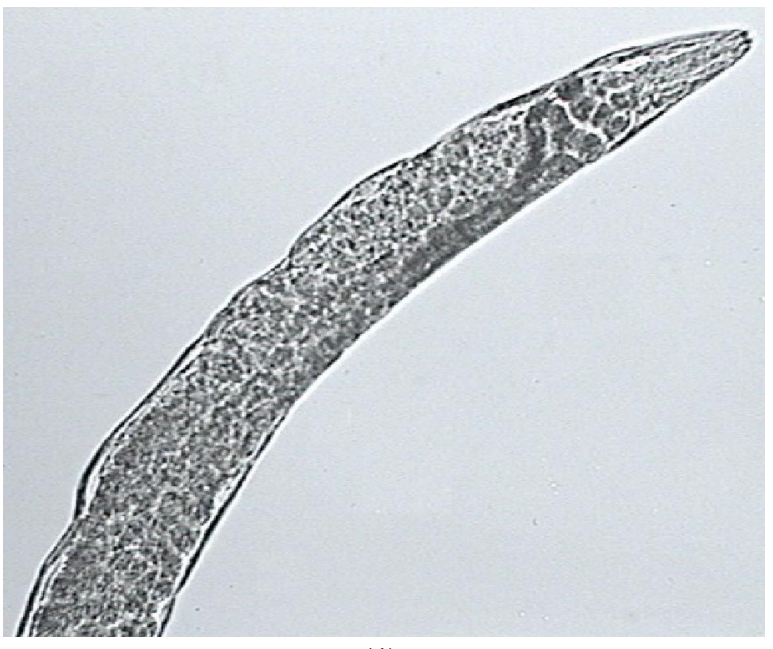

(1)

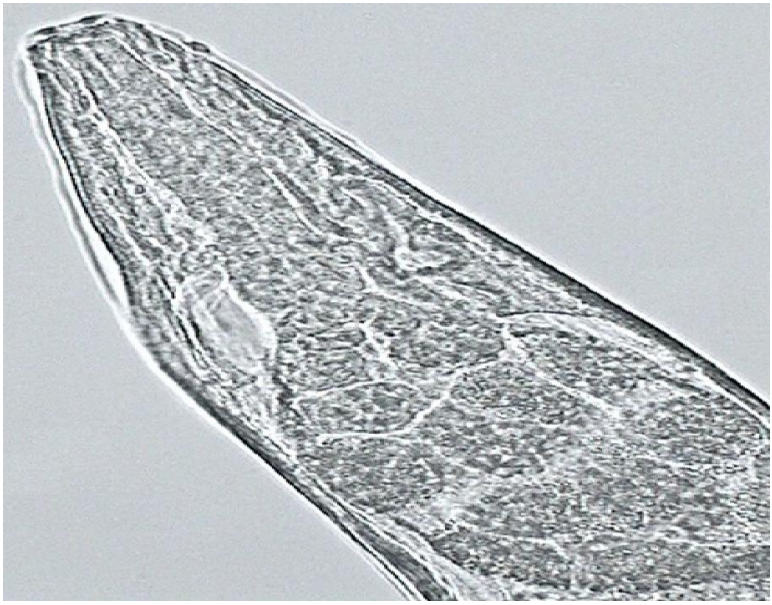

(2)

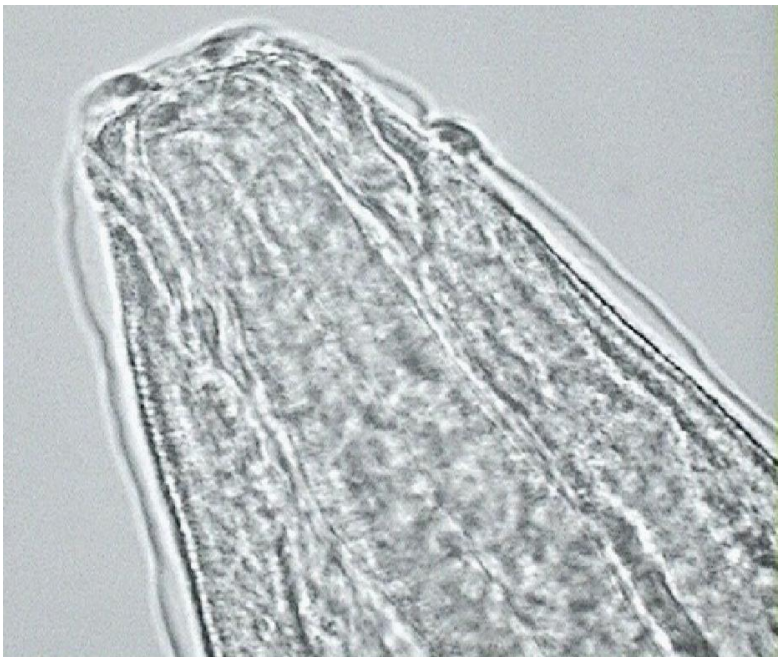

(3)

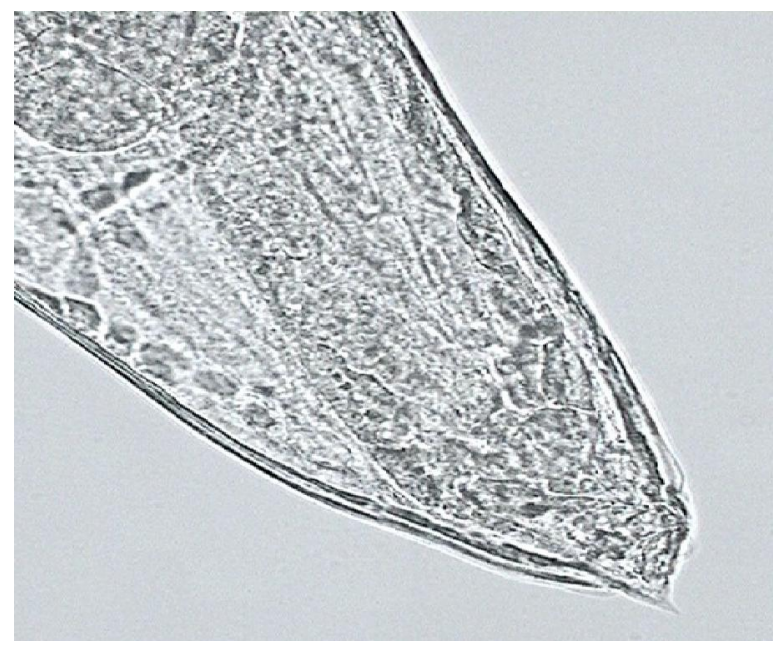

(4)

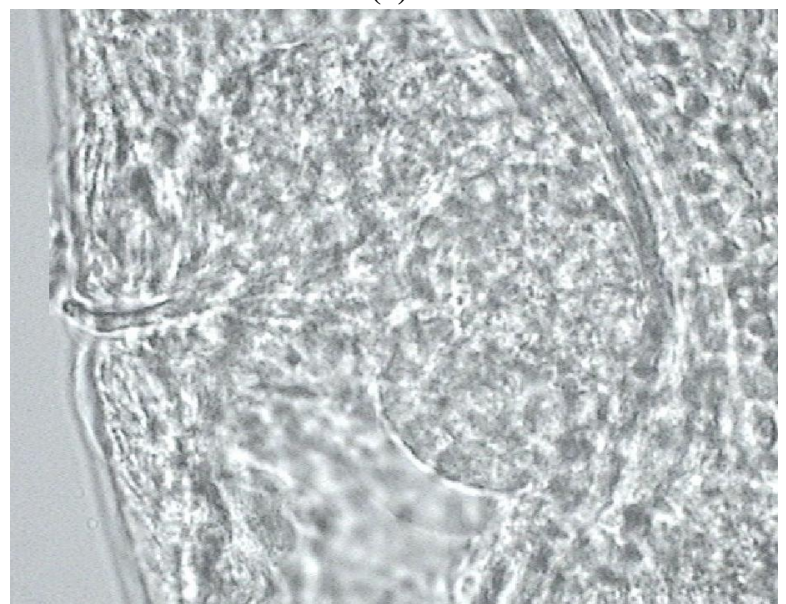

(5)

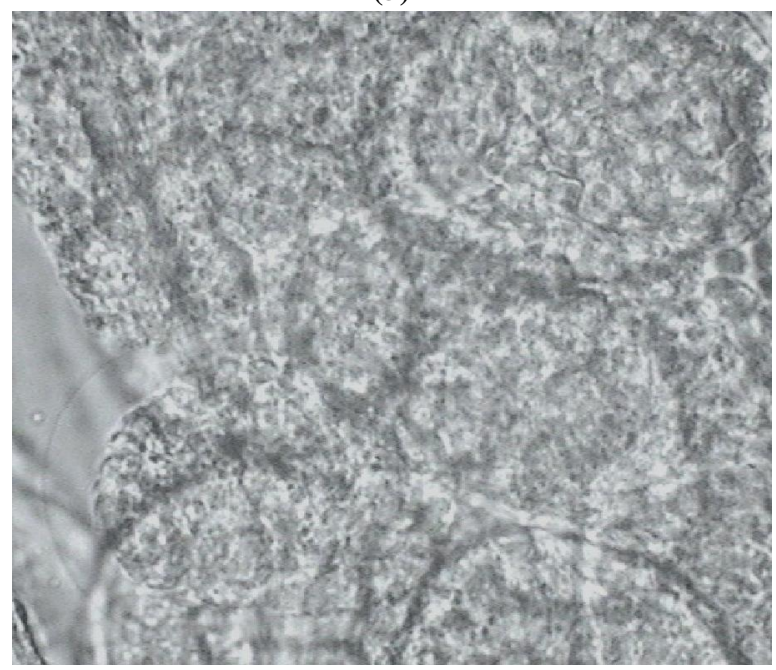

(6)

Plate IV. Steinernem scapterisci Nguyen and Smart 1990 female.Figs. 1-6. 1) Photomicrographs of anterior region x 100, 2) Photomicrographs of anterior region $\times 400,3$ ) Photomicrographs of anterior region $\times 1000,4$ ) Photomicrographs of posterior region $\times 400,5$ ) Vulva region $\times 1000,6)$ Eggs $\times 1000$.

different host or this could also be due to difference in zoogeographical niche of the parasite. Since these features are not of sufficient taxonomic merit. Thus can be treated as variations only.

Earlier, Nguyen and Smart (1990) have not mentioned any thing about the intestinal vesicle. But since this structure is very important as far as applications of nematode as biological control agents is concerned. These vesicles are present immediately behind the oesophageal bulb in the form of two pockets. Each having 
intravesicular structures. Presence of such structures have also been reported by Bird and Akhurst (1983), Endo and Nickle (1995) and Martens and Goodrich Blair (2005). Martens and Goodrich (2005) were of opinion, that, these intestinal vesicle contains subcellular structure with which microbes are found associated. These microbes in fact appear to be the pathogenic to the host species in which this nematode is found parasitizing.

\section{ACKNOW LEDGEMENTS}

The authors are thankful to the Head, Department of Zoology, C. C. S. University, Meerut, for providing laboratory facilities and valuable suggestions. Authorities of DST are gratefully acknowledged for financial assistance.

\section{REFERENCES}

Amara Singhe L.D., Hominick, W. M., Briscoe, B. R. and Reid, A. P. (1994). Occurrence and distributionof entomopathogenic nematodes in Sri Lanka. J ournal of H elminthology, 68: 277 . 286.

Bird A.F. and Akhurst R.J. (1983). The nature of the intestinal vesicle in nematodes of the family Steinernematidae. Int J Parasitol., 13 : 599-606.

Choo H.Y., Kaya H.K. and Stock S.P.(1995). Isolation of entomopathogenic nematodes (Steinernematidae and Heterorhabditidae) from Korea. J apanese J ournal of Nematology 25: 45-51.

Davies, R. G. (1977). I mms G eneral Textbook of Entomology. Champam and Hall, New York.

Endo, B.Y. and Nickle, W. R. ( 1995). Ultrastructure of anterior and mid regions of infective juveniles of Steiner nema feltiae. Fundam. Appl. Nematol., 18: 271-294.

Gaugler, R. and Kaya, H. K. (1990). Entomopathogenic nematodes in biological control. Boca Raton, Florida: CRC Press, 365 pp.
Imms A.D. (1960). A General Textbook of Entomology, Methuen London.

Jian B., Reid, A. P. and Hunt, D. J. (1997). Steinernema ceratophorum n.sp. (Nematoda: Steinernematidae) a new Entomopathogenic nematoda from north east. China. Syst. Parasitol., 37: 115-12

Kaya, H.K. and Gaugler, R. (1993). Entomopathogenic nematodes. Annual Review of Entomolgy, 38: 181-206.

Martens, E. C. and Goodrich Blair, H. (2005). The Steinernema carpocapsae intestinal vesicle contains a subcellular structure with which Xenorhabdus nematophila associates during colonization intiation. Cellular M icrobiology, 7: 1723-1735.

Mracek, Z. and Webster, J.M. (1993). Survey of heterorhabditidae and steinernematidae (Rhabditida, Nematoda) in Western Canada. J ournal of N ematology, 25: 710-717.

Nguyen, K. B. and Smart G. C. Jr. (1990). Steinernema scapterisci n.sp. (Steinernematidae: Nematoda).J ournal of Nematology, 22: 187-199.

Roman, J. and Figueroa, W. (1994). Steinernema puertoricensis n.sp. (Rhabditida, Steinernematidae) a new entomopathogenic nematode from Puerto Rico. J ournal of Agriculture, U niversity of Puerto Rico, 78: 167-175.

Rosa, J. S., Martins, A., Mendes, C., Amaral, J. J., Lacey, L.A. and Simoes, N. (1994). Natural occurrence of soil entomopathogens in the Azores Islands. Abstracts VIth International celloquium on Invertebrate Pathology and Microbial Control, 2: 275-276.

Stock S.P. (1995). Isolation of entomopathogenic nematodes from the Pampean region of Argentina. Nematropica, 25: 143-148.

Stock, S. P., Choo, H.Y. and Kaya H. K. (1997). An entomopathogenic nematode, Steinernema monticolum (Rhabditida: Steinernematidae) from Korea with a key to other species. Nematologica, 43: 15-29.

Travassos L. (1927). Sobre O genera 0 xystomatium. Boletin Biologica, 5: 20-21. 